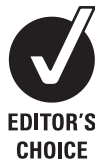

CHOICE

\title{
Long-term effectiveness of behavioural interventions to prevent smoking among children and youth
}

\author{
F Müller-Riemenschneider, ${ }^{1}$ A Bockelbrink, ${ }_{1}^{1}$ T Reinhold, ${ }^{1}$ A Rasch, ${ }^{2}$ W Greiner, ${ }^{2}$ \\ S N Willich ${ }^{1}$
}

${ }^{1}$ Institute for Social Medicine, Epidemiology and Health Economics, Charité University Medical Center, Berlin, Germany; ${ }^{2}$ Health Economics and Health Care Management, University of Bielefeld, Bielefeld, Germany

Correspondence to: Dr Falk Müller-Riemenscheider Institute for Social Medicine,

Epidemiology and Health

Economics, Charité University

Medical Center, 10098 Berlin,

Germany; falk.mueller-

riemenschneider@charite.de

Received 14 November 2007

Accepted 13 May 2008

Published Online First

3 June 2008

\begin{abstract}
Objectives: To evaluate the long-term effectiveness of recent behavioural interventions in the prevention of cigarette use among children and youth and to compare the effectiveness of different school-based, communitybased and multisectorial intervention strategies.

Methods: A structured search of databases and a manual search of reference lists was conducted. Randomised controlled trials published in English or German between August 2001 and August 2006 targeting youths up to 18 years of age were assessed independently by two researchers according to predefined inclusion criteria and with regard to methodological quality. Data abstraction was performed and crosschecked by two researchers. Where appropriate, pooled effect estimates were calculated and tested in sensitivity analyses.
\end{abstract}

Results: Of 3555 articles, 35 studies met the inclusion criteria. The follow-up duration ranged from 12 months to 120 months. Although the overall effectiveness of prevention programs showed considerable heterogeneity, the majority of studies reported some positive long-term effects for behavioural smoking prevention programs. There was evidence that community-based and multisectorial interventions were effective in reducing smoking rates; in contrast, the evidence for school-based programs alone was inconclusive. Regardless of the type of intervention, the reductions observed in smoking rates were only modest.

Conclusions: The present work identified moderate evidence for the effectiveness of behavioural interventions to prevent smoking. Although evidence for the effectiveness of school-based interventions was inconclusive, evidence for the effectiveness of community-based and multisectorial interventions was somewhat stronger. Future research should investigate the effectiveness of specific intervention components and the cost-effectiveness of interventions analysed in methodologically highquality studies.

The hazardous health effects of smoking and second-hand smoke are well known and have been confirmed in numerous studies. In industrialised countries, tobacco smoke is the single most common preventable risk factor for many chronic and potentially life-threatening conditions, such as respiratory, cardiovascular and malignant disease..$^{1-5}$ The World Health organization (WHO) has estimated that, annually, some 5 million deaths worldwide can be attributed to cigarette smoking. ${ }^{6}$ Despite this knowledge, the number of individuals who smoke, especially among children and adolescents, remains high or has even increased in recent years in most countries. ${ }^{78}$ Because the majority of smokers become addicted during adolescence, behavioural strategies have often aimed at preventing the initiation of smoking among children and youth. ${ }^{910}$ Traditionally, school-based prevention programs have been used as a way to reach as many children and adolescents as possible. However, because the effectiveness of early behavioural prevention strategies has often been limited or has even led to an increase in smoking rates, prevention programs have been continuously revised since their earliest iterations. ${ }^{11}{ }^{12}$ Whereas the first programs aimed at providing smoking-.related health information, later programs have pursued strategies based on social competence or social influence. ${ }^{13-17}$ Despite these ongoing developments, the evidence regarding the long-term effectiveness of school-based smoking prevention strategies remains limited. Many prevention strategies appear to be effective in the short term, but their long-term effectiveness is often disappointing. ${ }^{18-20}$ To overcome these limitations, school-based prevention programs have become more comprehensive in recent years, combining a variety of approaches. ${ }^{21}{ }^{22}$ Moreover, a number of community-based or multisectorial prevention programs (ie, encompassing school-and communitybased approaches) have been implemented in recognition of the multifactorial concept of smoking initiation among youth..$^{23-25}$ The aim of this systematic review is thus to evaluate the long-term effectiveness of recent behavioural interventions in the prevention of cigarette use among children and youth. A further objective is to compare the effectiveness of different school-based, communitybased and multisectorial interventions and to identify the effective components within them.

\section{METHODS}

Relevant publications were identified through a structured search of the following databases, accessed through the German Institute of Medical Documentation and Information (DIMDI): German Agency for Health Technology Assessment (DAHTA); International Network of Agencies for Health Technology Assessment (INAHTA) (National Health Service (NHS)Centre for Reviews and Dissemination (CRD)Health Technology Assessment (HTA)); NHS Economic Evaluation Database (NHSEED); Cochrane Database of Abstracts of Reviews of Effectiveness (CDAR94) (NHS-CRD-Database of Abstracts of Reviews of Effects (DARE)); Cochrane Database of Systematic Reviews (CDSR93); ME00 (Medline); EM00 (EMBASE); CB85 (Allied and Complementary Medicine Database (AMED)); BA90 (BIOSIS Previews); MK77 (MEDIKAT); 
Cochrane Central Register of Controlled Trials (CCTR93); GA03 (German Medical Science (gms)); SM78 (SozialMedizin (SOMED)); CV72 (Centre for Agriculture and Biosciences (CAB) Abstracts); II78 (Index to Scientific and Technical Proceedings and Books (ISTPB) + Index to Social Sciences and Humanities Proceedings (ISSHP)); ED93 (Ethics in Medicine (ETHMED)); AZ72 (GLOBAL Health); AR 96 (Deutsches Ärzteblatt); ME0A (Medline Alert); EA08 (EMBASE Alert); IS90 (SciSearch); CC00 (CCMed); IN73 (Social SciSearch); KR03 (Karger Publisher Database); KL97 (Kluwer Verlagsdatenbank); SP97 (Springer Verlagsdatenbank); SPPP (Springer Verlagsdatenbank PrePrint); TV01 (Thieme Verlagsdatenbank).

In addition, a manual search of reference lists included in the articles identified as part of the structured database search described above was conducted. The present review includes German and English literature published between August 2001 and August 2006 and targeting youth up to 18 years of age. Randomised controlled trials (RCTs) were included if they were of a duration of at least 12 months and reported the outcome as a measure of smoking behaviour. When a trial was reported in multiple publications, the latest follow-up outcomes were taken into account. The titles, abstracts and full-texts of all identified studies were reviewed independently by two researchers and evaluated with regard to their methodological quality using standardised quality checklists employed by DIMDI. These checklists consider the following aspects: selection process of intervention and control participants, allocation method, comparability of intervention groups, consideration of relevant confounders, blinding (single/double), comparability of circumstances beyond the intervention, validity of outcome assessment, attrition rate/differential attrition, description of statistical methods and intention to treat analysis.

Depending on the risk of bias, studies were subsequently rated as being of high (minimal risk of bias), good (moderate risk of bias), or fair (high risk of bias) methodological quality according to the grading system developed by the Scottish Intercollegiate Guidelines Network Review Group (SIGN) ${ }^{26}$ For all of the studies included in this review, data were extracted by one researcher and crosschecked by another. Disagreements between researchers in any matter related to the study selection process or data abstraction were resolved in discussion.

Interventions were classified as school-based, communitybased or multisectorial, depending on the main components of the intervention. Any intervention performed outside the school environment was considered community-based; in turn, multisectorial interventions were defined as consisting of a school and an out-of-school component. To compare the effectiveness of the interventions, qualitative and quantitative synthesis of study results was performed and based, if possible, on studies with a small to moderate risk of bias. Our meta-analysis included studies only if these reported suitable prevalence data or effect measures. Odds ratios were calculated for dichotomous outcome measures. Pooled effects were subsequently estimated using a generic inverse variance method with random effects, as described in the Cochrane Handbook for Systematic Reviews. ${ }^{27}{ }^{28}$ Pooled effect estimates were calculated for reported outcomes of lifetime, 30-day and regular smoking. To avoid double counting of individual studies, pooled estimates across these outcome categories were not calculated.

In the sensitivity analysis, we included fair-quality studies reporting suitable outcome data, excluded outliers and calculated pooled estimates using fixed effect models. In studies lacking suitable outcome data, it was attempted (whenever possible) to derive the number of smokers and non-smokers from the percentages given in these studies. To investigate the possibility of publication bias, a funnel plot diagram was constructed, including previously calculated effect estimates and standard errors of all identified studies and all suitable outcome measures.

\section{RESULTS}

A total of 3555 publications were identified as part of a systematic search. Of these, 45 publications covering a total of 35 studies met the inclusion criteria (fig 1). The majority of studies were large and carefully conducted cluster randomised trials, which consisted of complex and resource intensive intervention strategies. It was therefore possible to rate more than half of these as being of good or high methodological quality. Reasons for limited methodological quality included inadequate descriptions of allocation methods; missing descriptions of baseline characteristics or of statistical analysis; and low follow-up rates. In addition, only a limited number of studies blinded participants or investigators to the intervention, validated outcome measures, or performed an intention-to-treat analysis. Follow-up duration ranged from 12 to 120 months.

The main study characteristics and individual study outcomes are presented in tables 1-3. Although the overall effectiveness of prevention programs showed considerable heterogeneity, the majority of studies reported at least some evidence of a positive intervention effect.

\section{School-based interventions}

Among 14 randomised studies investigating school-based interventions, 9 were of good to high methodological quality. Of these, only Botvin et $a^{29}$ and Johnson et al ${ }^{30}$ reported clearly positive intervention effects. In part, these effects were restricted to the culturally adapted intervention. ${ }^{30}$ The results of the seven remaining studies were inconclusive or even indicated that the intervention effects had been unfavourable. ${ }^{31-33}$ Differences in smoking rates between intervention groups varied considerably across studies, ranging from $-3.8 \%$ (ie, favouring intervention groups) to $5.4 \%$ (ie, favouring control groups) (table 1). The results of our meta-analysis provide no evidence for the long-term effectiveness of school-based interventions (fig 2). These findings were similar for lifetime, 30-day and regular smoking. In our sensitivity analysis, the positive effects reached borderline significance when including fair-quality studies (table 4).

\section{Community-based interventions}

Among 10 studies investigating community-based interventions, 7 were of good to high methodological quality. Of these, Hollis et $a l^{34}$ Jackson et al, ${ }^{35}$ Fidler et $a l^{36}$ and Stanton et a ${ }^{37}$ reported strong evidence of intervention effectiveness, as demonstrated by reductions in smoking rates of up to $10.6 \%$. Conversely, Curry et $a l^{25}$ and Stevens et $a^{138}$ reported a trend towards unfavourable intervention effects, reflecting an increase in smoking rates of up to $1.5 \%$ within the intervention group (table 2). Qualitative data synthesis was consistent with the results of our meta-analysis. Estimated pooled effects provided some evidence for the long-term effectiveness of communitybased interventions (fig 3). The pooled effects were robust to sensitivity analysis, as presented in table 4.

\section{Multisectorial interventions}

Among 11 studies investigating multisectorial interventions, 6 were of good to high methodological quality. The studies by Ellickson et $a l,{ }^{39}$ Furr-Holden et $a l,{ }^{40}$ Reddy et $a l^{41}$ and 
Figure 1 Flowchart of study selection.

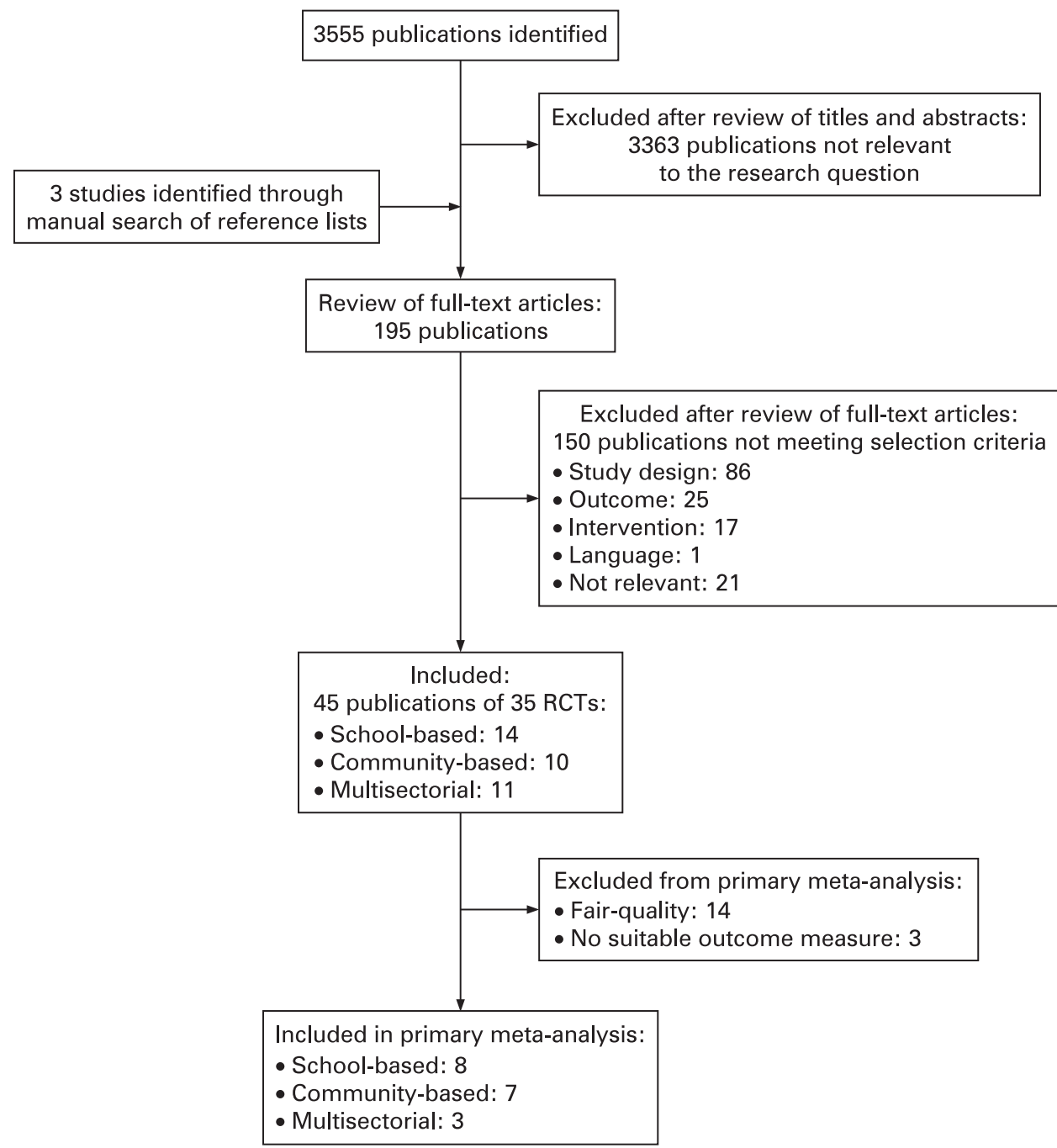

Simons-Morten et al ${ }^{42}$ reported strong evidence of long-term effectiveness, and Perry et $a l^{43}$ and Spoth et $a l^{44}$ reported positive intervention effects for only some groups. One study reported different outcome measures for smoking behaviour, indicating similar intervention effects, ${ }^{39}$ and none of the studies identified found any association between the intervention strategies and unfavourable effects on smoking rates. The difference in smoking rates between intervention and control groups was as high as $6.1 \%$, favouring the intervention group in all cases (table 3). A total of three studies did not report smoking prevalence or effect estimates as an outcome measure. Consequently, our meta-analysis was restricted to a limited number of studies. The results of the pooled effect estimates, however, provide strong evidence of the effectiveness of the intervention and were therefore consistent with the qualitative synthesis of data (fig 4). The estimated pooled effects were also robust to sensitivity analysis, being less strong only when studies with less reliable methodology were taken into consideration. The differences between intervention and control groups remained, however, statistically significant (table 4).

Few studies specifically tested different intervention strategies against each other. Spoth et a l $^{44}$ observed a greater reduction in smoking rates when school-based life skills training and an additional family-strengthening intervention were used. This difference did not reach statistical significance, however. Similarly, Perry et al ${ }^{43}$ observed substantial intervention effects associated with the DARE-Plus intervention compared to the DARE intervention, although only among boys. Conversely, Furr-Holden et al ${ }^{40}$ demonstrated that, compared to control, a classroom-centred intervention had greater intervention effects than did a family-school partnership; however, these two interventions were not formally tested against one another.

\section{Intervention components}

Few studies investigated the individual components of interventions. In the context of community-based and multisectorial programs, family interventions were frequently used. These pursued a variety of strategies, such as informing parents, improving parent-child communication, or strengthening the parent-school partnership. Whereas Stanton et $a^{37}$ and FurrHolden et $a l^{40}$ reported reductions in smoking rates associated with parental interventions, Schinke et al ${ }^{45}$ reported no additional benefits. Spoth et $a^{44}$ also pointed to some additional effects for the family-strengthening intervention. The difference between intervention groups did not reach statistical significance, however. Although substantial reductions in smoking rates were also reported by Jackson et al ${ }^{35}$ these investigators did not explore the additional effect beyond interventions focused on children. This all being said, only one study reported a trend towards unfavourable outcomes associated with family interventions. ${ }^{25}$ Although a number of additional studies that 
Table 1 School-based interventions

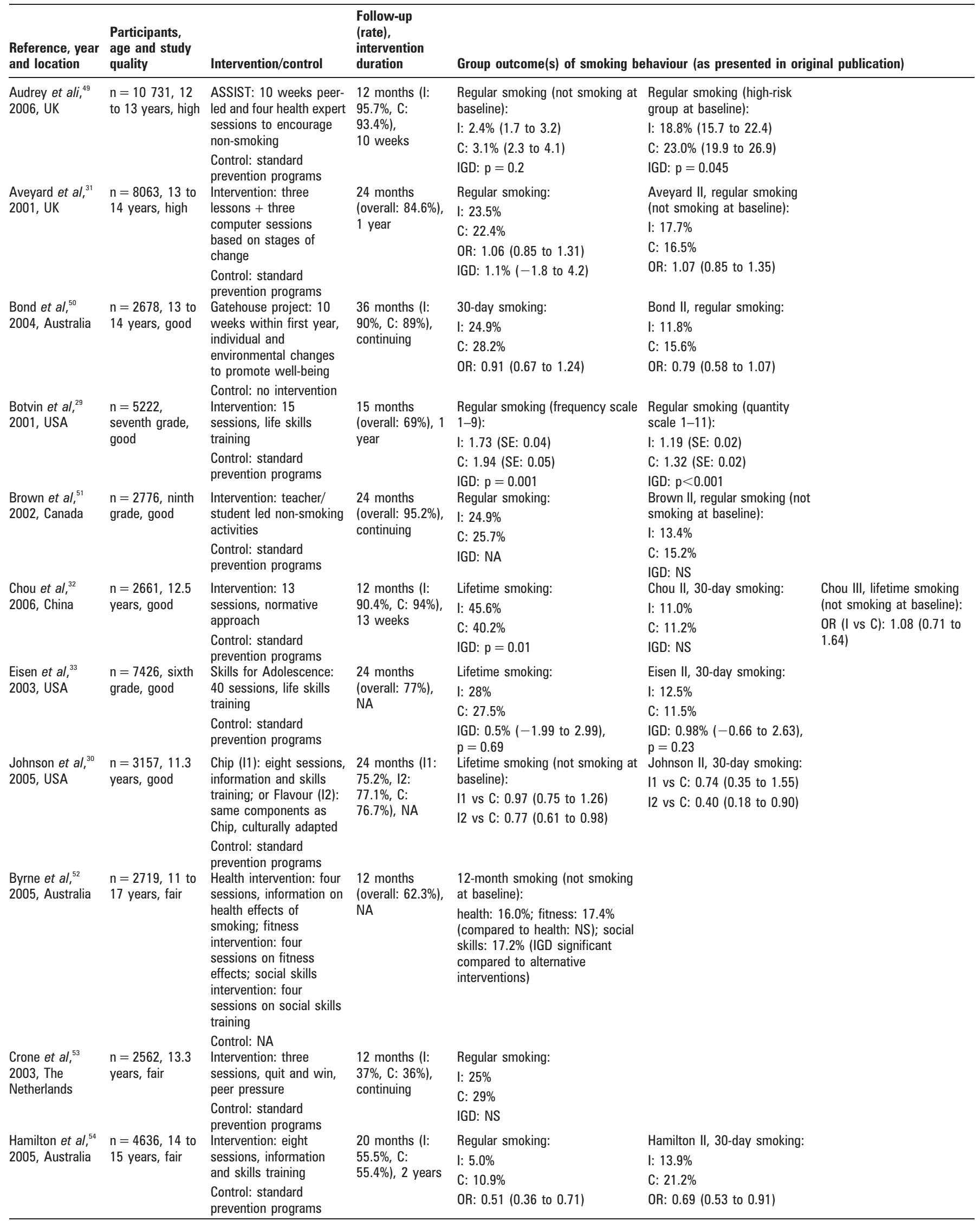


Table 1 Continued

\begin{tabular}{|c|c|c|c|c|c|}
\hline $\begin{array}{l}\text { Reference, year } \\
\text { and location }\end{array}$ & $\begin{array}{l}\text { Participants, } \\
\text { age and study } \\
\text { quality }\end{array}$ & Intervention/control & $\begin{array}{l}\text { Follow-up } \\
\text { (rate), } \\
\text { intervention } \\
\text { duration }\end{array}$ & Group outcome(s) of smoking b & ehaviour (as presented in original publication) \\
\hline $\begin{array}{l}\text { Schulze et al, }{ }^{55} \\
\text { 2006, Germany }\end{array}$ & $\begin{array}{l}\mathrm{n}=4043, \text { no } \\
\text { information, fair }\end{array}$ & $\begin{array}{l}\text { Intervention: quit and } \\
\text { win, peer pressure } \\
\text { Control: standard } \\
\text { prevention programs }\end{array}$ & $\begin{array}{l}18 \text { months } \\
\text { (overall: } 42 \% \text { ), } \\
\text { continuing }\end{array}$ & $\begin{array}{l}\text { Regular smoking: } \\
\text { I: } 38.7 \% \\
\text { C: } 40.1 \% \\
\text { IGD: NA }\end{array}$ & $\begin{array}{l}\text { Regular smoking (not smoking } \\
\text { at baseline): } \\
\text { I: } 37.9 \% \\
\text { C: } 38.5 \% \\
\text { OR (I vs } 1.02 \text { (0.83 to } 1.24)\end{array}$ \\
\hline $\begin{array}{l}\text { Share et al, }{ }^{56} \\
2004 \text {, Ireland }\end{array}$ & $\begin{array}{l}\mathrm{n}=620,9 \text { to } 10 \\
\text { years, fair }\end{array}$ & $\begin{array}{l}\text { Intervention: sessions } \\
\text { with smoking related } \\
\text { information and activities } \\
\text { Control: NA }\end{array}$ & $\begin{array}{l}60 \text { months (no } \\
\text { information), } \\
\text { continuing }\end{array}$ & $\begin{array}{l}\text { Lifetime smoking: } \\
\text { I: } 59 \% \\
\text { C: } 55 \% \\
\text { IGD: NA }\end{array}$ & $\begin{array}{l}\text { Regular smoking: } \\
\text { I: } 19 \% \\
\text { C: } 24 \% \\
\text { IGD: NA }\end{array}$ \\
\hline $\begin{array}{l}\text { Sussman et al, } \\
2003 \text {, USA }\end{array}$ & $\begin{array}{l}\mathrm{n}=1037,14 \text { to } \\
19 \text { years, fair }\end{array}$ & $\begin{array}{l}\text { Health expert- } \\
\text { intervention (I1): } 12 \\
\text { sessions, social skills } \\
\text { and decision training by } \\
\text { experts; self-instruction- } \\
\text { intervention (I2): same } \\
\text { content by self- } \\
\text { instruction } \\
\text { Control: standard } \\
\text { prevention programs }\end{array}$ & $\begin{array}{l}24 \text { months (I1: } \\
55 \%, \text { I2: } 55 \%, \mathrm{C} \text { : } \\
57 \%) \text {, NA }\end{array}$ & $\begin{array}{l}\text { OR (I vs C): } \\
\mathrm{I}_{1}: 0.50(0.31 \text { to } 0.81), p=0.016 \\
\mathrm{I}_{2}: 0.88(0.63 \text { to } 1.12), \mathrm{p}=0.253\end{array}$ & \\
\hline
\end{tabular}

Author names followed by II, III or abbreviation represent additional outcome measures in meta-analysis. If given, ranges in parentheses are $95 \%$ Cls. Interventions are given by program name, where applicable. Grade refers to school grade.

ASSIST, A Stop Smoking In Schools Trial; IGD, intergroup difference; C, control; I, intervention; OR, odds ratio; NS, not significant; NA, not available; SE, standard error.

included family components also reported evidence of long-term effectiveness, it is impossible to distinguish the family component from the overall intervention effect. ${ }^{39} 41-434647$

Only the study by Stanton et al ${ }^{37}$ examined the additional effectiveness of booster strategies to maintain intervention effects over time. They found no further reductions in smoking rates associated with this strategy. Nonetheless, with two exceptions $^{33}{ }^{47}$ several additional studies using booster strategies or continuing intervention sessions over the study duration reported reductions in smoking rates associated with the intervention. . $^{33} 353638-4042444750$ However, the effectiveness of these maintenance strategies was not examined specifically in any of these studies.

Three identified community-based studies investigated the effectiveness of primary care interventions compared to nointervention control groups. ${ }^{34}{ }^{36} 38$ The studies by Hollis et a l $^{34}$ and Fidler $e t a^{36}$ reported strong evidence of intervention effectiveness, whereas Stevens et al ${ }^{38}$ reported a trend towards an increase in smoking rates associated with the prevention program.

\section{DISCUSSION}

To our knowledge, the present work is the first to include and compare school-based, community-based and multisectorial behavioural interventions in the prevention of cigarette smoking among children and youth. As was expected, marked heterogeneity in intervention strategies, study methodology and intervention effectiveness were observed. Although reported effectiveness of investigated interventions varied between studies, the majority of studies provided at least some evidence for the effectiveness of behavioural interventions in the prevention of smoking. Frequently, studies reported different outcome measures of smoking behaviour. However, for the most part, the intervention effects appeared to remain consistent across these reported outcomes. With regard to different age groups, only two methodologically reliable studies targeted children between 5 and 10 years. These studies found strong evidence of intervention effectiveness. Whether this indicates that smoking prevention strategies have differential effects depending on age will require further investigation. ${ }^{35} 40$

When comparing different intervention strategies, the present review revealed the evidence for the effectiveness of schoolbased interventions to be inconclusive, whereas the evidence for the effectiveness of community-based and multisectorial interventions was somewhat stronger. These findings were consistent with the qualitative and quantitative synthesis of study results and were robust, for the most part, to sensitivity analysis.

The present review provides new insight into the debate about the long-term effectiveness of school-based interventions. Although a number of systematic reviews investigating this subject have concluded that school-based interventions can be effective in the long term, ${ }^{19}{ }^{20}$ this review does not provide convincing support of these earlier findings. Although only recent school-based interventions were included in this review, clearly positive intervention effects were restricted to two studies. ${ }^{29} 30$ One of these took a culturally adapted approach and targeted a very specific population group, ${ }^{30}$ whereas the other ${ }^{29}$ presented results only as an aggregated outcome measure, thereby limiting comparability. The results of the remaining studies were inconclusive or even showed school-based interventions to be associated with increases in smoking rates. These findings were consistent with our meta-analysis, which was also unable to provide evidence for the effectiveness of schoolbased interventions. The findings of the present review thus confirm the conclusions drawn in a Cochrane review by Thomas et al, ${ }^{48}$ which did not find convincing evidence for the long-term effectiveness of school-based interventions. Whereas the conclusions of the Cochrane review were based, in large part, on one of the most sizeable studies investigating the socialinfluences approach in school-based smoking prevention (ie, the Hutchinson Smoking Prevention Trial), the present review included only recent school-based smoking-prevention strategies. Despite this focus on current prevention strategies, the outcome remained inconclusive.

With regard to the effectiveness of community-based and multisectorial interventions, the present review adds to previous 
Table 2 Community-based interventions

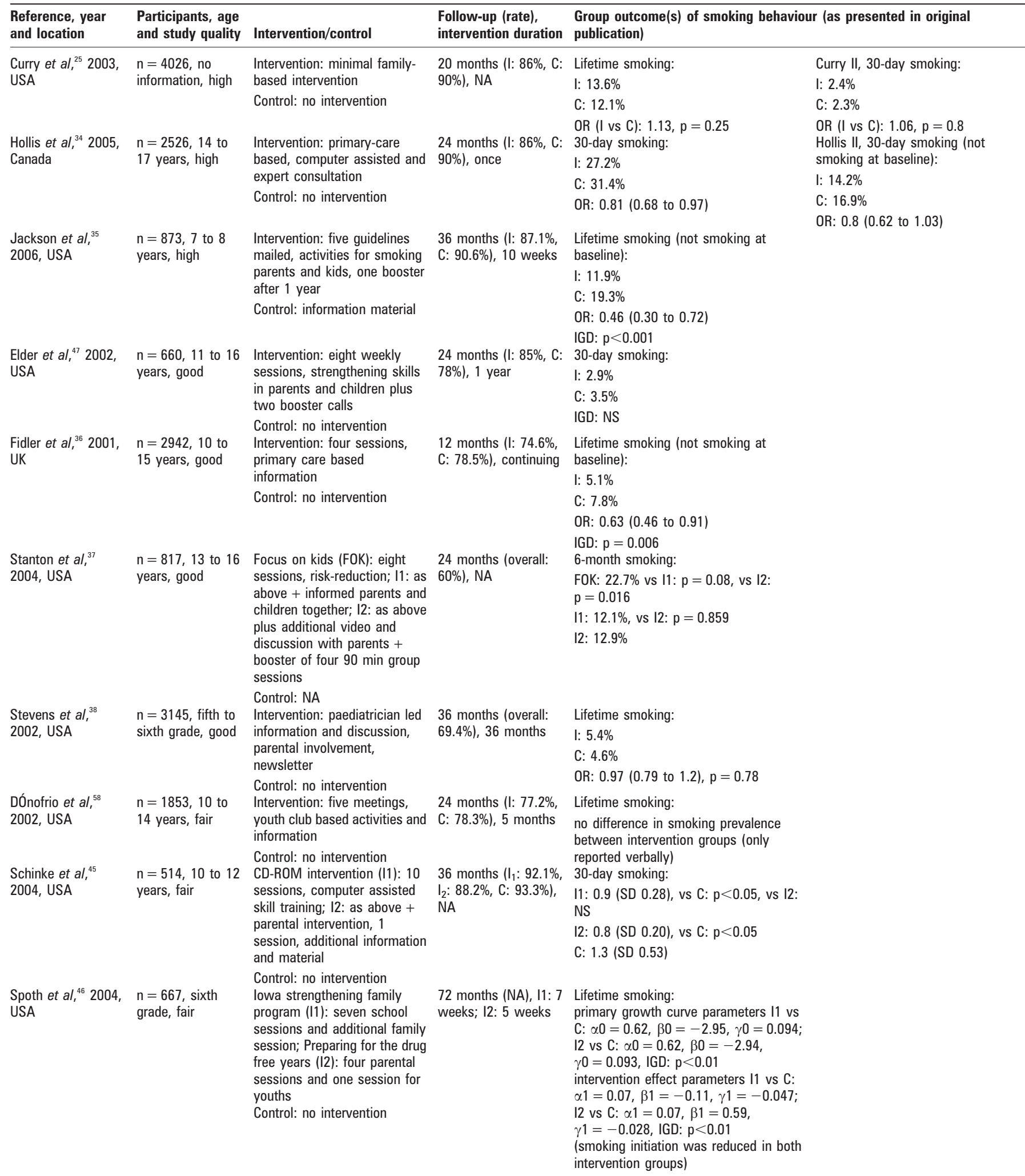

Author names followed by II, III or abbreviation represent additional outcome measures in meta-analysis. If given, ranges in parentheses are $95 \%$ Cls. Interventions are given by program name, where applicable. Grade refers to school grade.

IGD, intergroup difference; $\mathrm{C}$, control; I, intervention; $\mathrm{OR}$, odds ratio; NS, not significant; NA, not available.

research. Sowden et al ${ }^{23}$ identified 17 trials, 6 of which were randomised, in a review of community interventions. They reported positive intervention effects for only 2 out of 12 studies compared to a no-intervention control. The majority of studies included in their review investigated combinations of school-based and community-based interventions. Similarly, Thomas et $a l^{48}$ reported inconsistent evidence regarding the effectiveness of multisectorial interventions. By contrast, the majority of studies included in the present review, as well as the pooled effect estimates of studies investigating 
Table 3 Multisectorial interventions

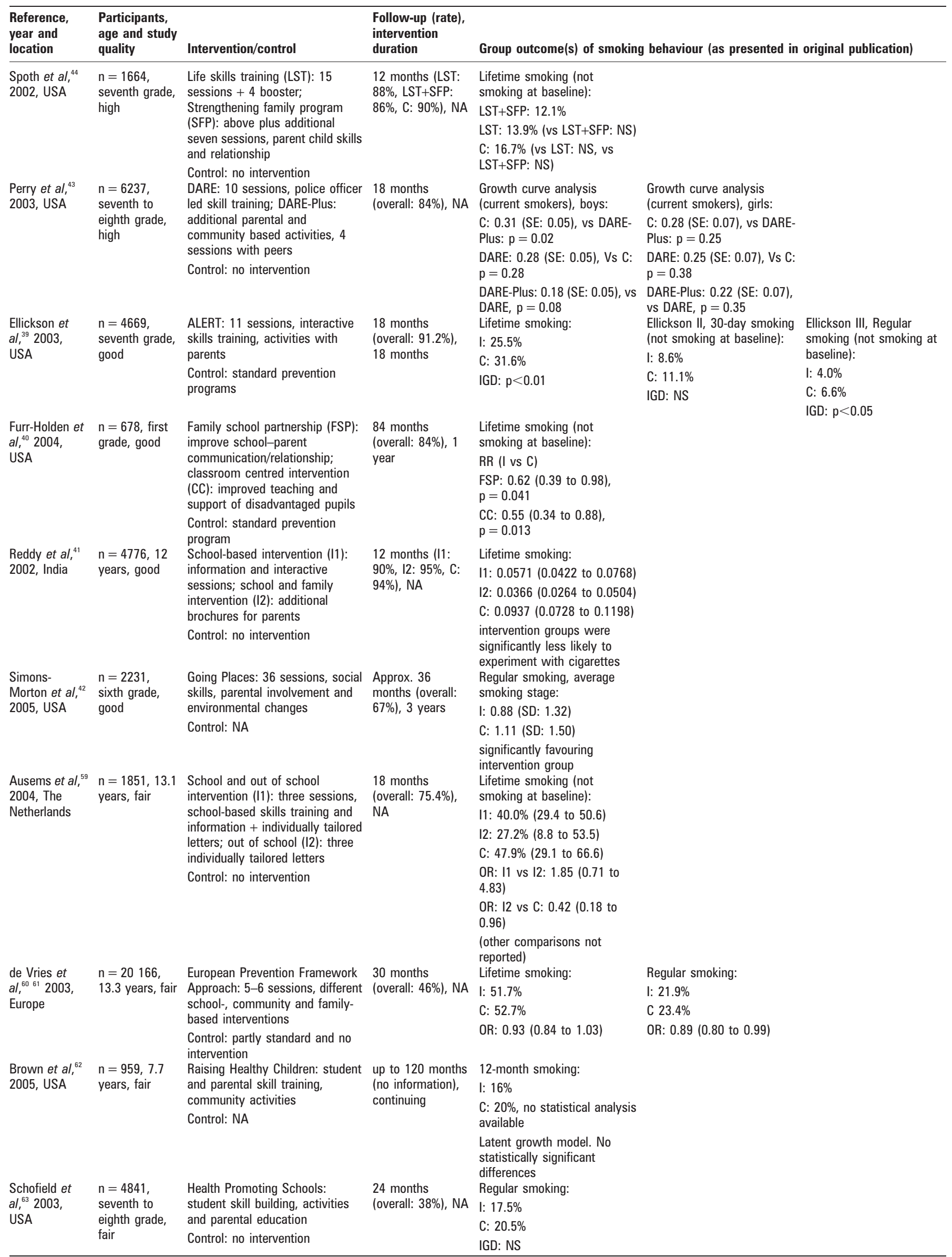


Table 3 Continued

\begin{tabular}{|c|c|c|c|c|c|c|}
\hline $\begin{array}{l}\text { Reference, } \\
\text { year and } \\
\text { location }\end{array}$ & $\begin{array}{l}\text { Participants, } \\
\text { age and study } \\
\text { quality }\end{array}$ & Intervention/control & $\begin{array}{l}\text { Follow-up (rate), } \\
\text { intervention } \\
\text { duration }\end{array}$ & \multicolumn{3}{|c|}{ Group outcome(s) of smoking behaviour (as presented in original publication) } \\
\hline $\begin{array}{l}\text { Winkleby et } \\
\text { al, }{ }^{64} 2004, \\
\text { USA }\end{array}$ & $\begin{array}{l}\mathrm{n}=798 \\
\text { eleventh to } \\
\text { twelfth grade, } \\
\text { fair }\end{array}$ & $\begin{array}{l}\text { Advocacy intervention: } 18 \\
\text { sessions, information and } \\
\text { development of community } \\
\text { activities } \\
\text { Control: modified "towards no } \\
\text { drug abuse" }\end{array}$ & $\begin{array}{l}12 \text { months (I: } \\
82 \%, \text { C: } 87 \%), 2 \\
\text { years }\end{array}$ & $\begin{array}{l}\text { Currently smoking: } \\
\text { I: } 44.6 \% \text { (SD 8.3) } \\
\text { C: } 39.1 \% \text { (SD 7.8) } \\
\text { IGD: } p=0.92 \text { (post } \\
\text { intervention to follow-up) }\end{array}$ & $\begin{array}{l}\text { Less than one pack/week: } \\
\text { I: } 35.1 \% \text { (SD 7.4) } \\
\text { C: } 35.3 \% \text { (SD 5.6) } \\
\text { IGD: } p=0.95\end{array}$ & $\begin{array}{l}\text { More than one pack/week } \\
\text { I: } 20.3 \% \text { (SD .7) } \\
\text { C: } 25.6 \% \text { (SD 4.9) } \\
\text { IGD: } p=0.97\end{array}$ \\
\hline
\end{tabular}

Author names followed by II, III or abbreviation represent additional outcome measures in meta-analysis. If given, ranges in parentheses are $95 \%$ Cls. Interventions are given by program name, where applicable. Grade refers to school grade.

ALERT, Project ALERT; DARE, Drug Abuse Resistance Education; IGD, intergroup difference; C, control; I, intervention; OR, odds ratio; NS, not significant; NA, not available; SE, standard error.

community-based and multisectorial interventions, found evidence of intervention effectiveness. While these findings indicate that evidence for the long-term effectiveness of community-based and multisectorial interventions is stronger and more consistent than has been shown in previous reviews, it has to be recognised that the study selection criteria and the classification of intervention strategies in the present review differed from those used in previous reviews.

The intervention effects reported for community-based and multisectorial strategies were not only more consistent than those observed for school-based strategies, they also resulted in a larger reduction in smoking rates. Indeed, whereas the greatest reduction in smoking rates among school-based strategies was only $3.6 \%$, community-based and multisectorial interventions reported reductions of up to $10 \%$.

Specific intervention components were investigated only infrequently. However, family-based interventions were used in many community-based and multisectorial intervention strategies. Although it was difficult to identify their specific impact, there seems to be some evidence for the additional effectiveness of this approach. In order to achieve reductions in smoking rates, however, it appears that providing smokingrelated information to parents was not sufficient on its own, but rather that the family members needed to be actively involved. Activities targeted at parents who smoke were found to be especially effective. Further research will be necessary to confirm these results and investigate the additional reductions in smoking rates associated with this approach.

In the community, alternatives to family interventions are interventions in the primary health care sector. Although there is evidence that such interventions can effectively reduce smoking rates, the relative effectiveness compared to alternative interventions remains unclear and absolute effect sizes were only modest.

Further, one study found evidence that culturally adapting the approach and materials of an intervention to the needs of specific population groups was more effective than standardised strategies. It would thus seem advisable to pursue the former approach to bring about more substantial reductions in smoking rates in specific populations. However, further research will be necessary to confirm these findings and evaluate the costeffectiveness of these more resource-intensive approaches.

The present review also attempted to determine whether the number of intervention sessions was associated with intervention effectiveness. Although the number of sessions varied greatly between minimal interventions and interventions with

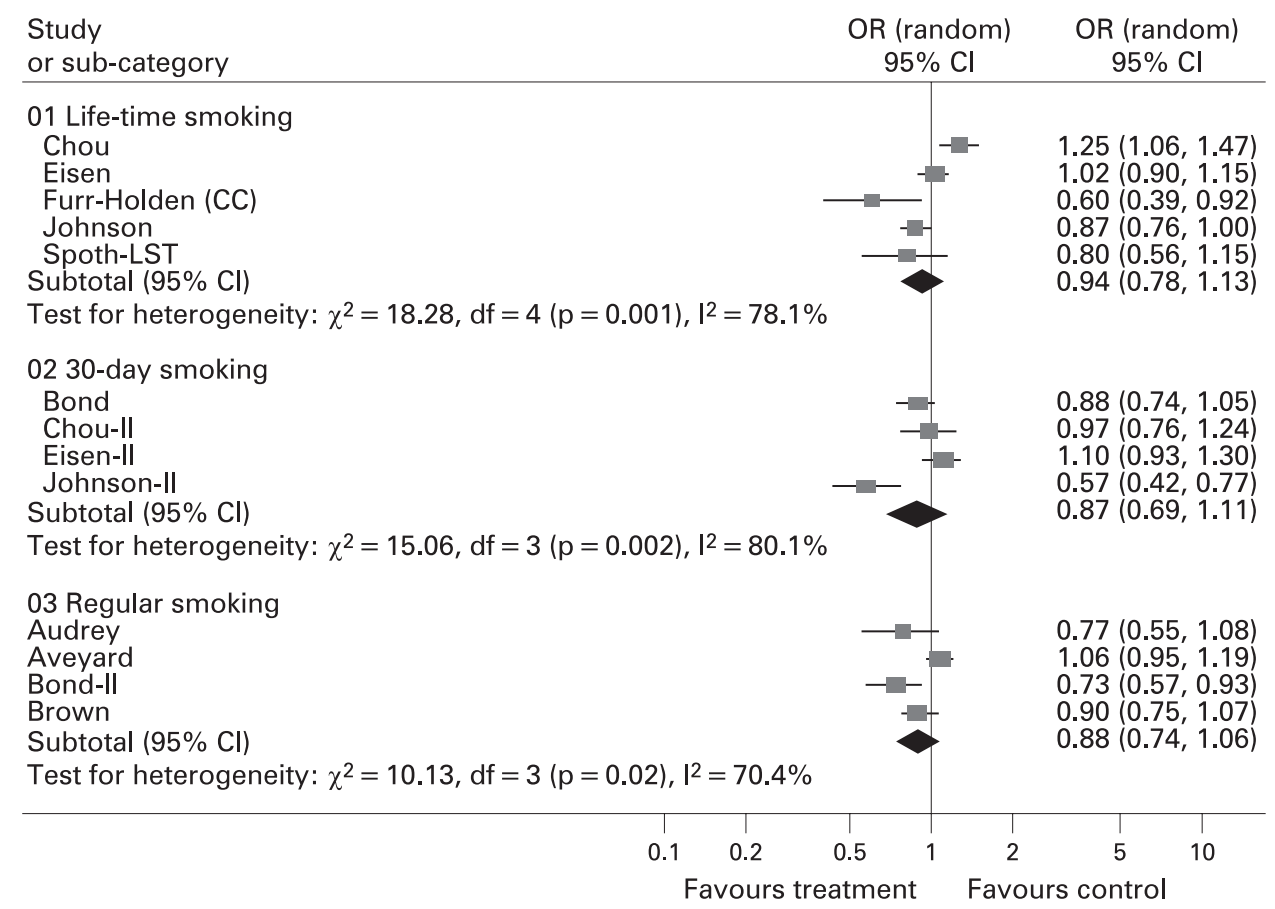

Figure 2 Meta-analysis of school-based interventions. 
Table 4 Sensitivity analyses with pooled effect estimates, 95\% Cls and no. of comparisons included in metaanalysis

\begin{tabular}{|c|c|c|c|}
\hline Analysis & Lifetime smoking & 30-day smoking & Regular smoking \\
\hline \multicolumn{4}{|l|}{ School-based: } \\
\hline Primary analysis & $0.94(0.78 \text { to } 1.13)^{*}$ & $0.87(0.69 \text { to } 1.11)^{*}$ & $0.88(0.74 \text { to } 1.06)^{*}$ \\
\hline No. of comparisons & 5 & 4 & 4 \\
\hline Including fair-quality studies & $0.95(0.80 \text { to } 1.13)^{*}$ & $0.79(0.64 \text { to } 0.97)^{*}$ & $0.80(0.67 \text { to } 0.95)^{*}$ \\
\hline No. of comparisons & 6 & 6 & 8 \\
\hline \multicolumn{4}{|l|}{ Community-based: } \\
\hline Primary analysis & $0.77(0.53 \text { to } 1.11)^{*}$ & $0.85(0.72$ to 0.99$)$ & \\
\hline No. of comparisons & 5 & 3 & \\
\hline Including fair-quality studies & $0.80(0.60 \text { to } 1.06)^{*}$ & 0.85 (0.72 to 0.99$)$ & \\
\hline No. of comparisons & 8 & 3 & \\
\hline \multicolumn{4}{|l|}{ Multisectorial: } \\
\hline Primary analysis & $0.73(0.64$ to 0.82$)$ & $0.79(0.61$ to 1.02$)$ & $0.59(0.42$ to 0.83$)$ \\
\hline No. of comparisons & 3 & 1 & 1 \\
\hline Including fair-quality studies & $0.79(0.68 \text { to } 0.92)^{*}$ & $0.79(0.61$ to 1.02$)$ & $0.87(0.79$ to 0.95$)$ \\
\hline No. of comparisons & 5 & 1 & 3 \\
\hline
\end{tabular}

$\left.{ }^{*}\right|^{2}>50 \%$.

up to 40 sessions, the majority of studies used between 5 and 15 sessions. None of the studies investigated this issue specifically, however, and studies did not provide evidence that the number of intervention sessions was associated with intervention effectiveness. Similarly, identified studies only provided limited evidence, that booster strategies can improve long-term intervention effectiveness. However, one high-quality, minimalintensity intervention ${ }^{25}$ showed a trend towards negative intervention effects, suggesting that a certain minimum amount of contact with participants might be necessary to achieve positive intervention effects.

When interpreting the outcomes of this systematic review and meta-analysis, several limitations should be kept in mind. Firstly, classifying interventions as school-based, communitybased, or multisectorial is not unproblematic from a methodological perspective. As can be expected in the broad field of tobacco prevention, these three categories actually include a very diverse set of interventions. Nevertheless, because many of the most recent intervention strategies have drawn upon a variety of theoretical concepts, this approach was considered the most consistent means of classification. In recognition of the drawbacks to this approach, however, the attempt was made to identify specific components within the various interventions. Secondly, because only a minority of studies specifically investigated different smoking prevention programs, our comparison of school-based, community-based and multisectorial interventions is mainly based on an indirect approach. While the few studies that compared different intervention strategies provided some indication that multisectorial interventions were more effective, the differences between schoolbased and multisectorial interventions rarely achieved statistical significance. 40414344 Thirdly, apart from the interventions, studies varied in a number of characteristics which could explain the varying degree of intervention effectiveness, such as country of study origin, methodological study quality, age and cultural background of participants. Also, control groups in community-based interventions were mainly described as "nointervention controls". However, standard prevention programs

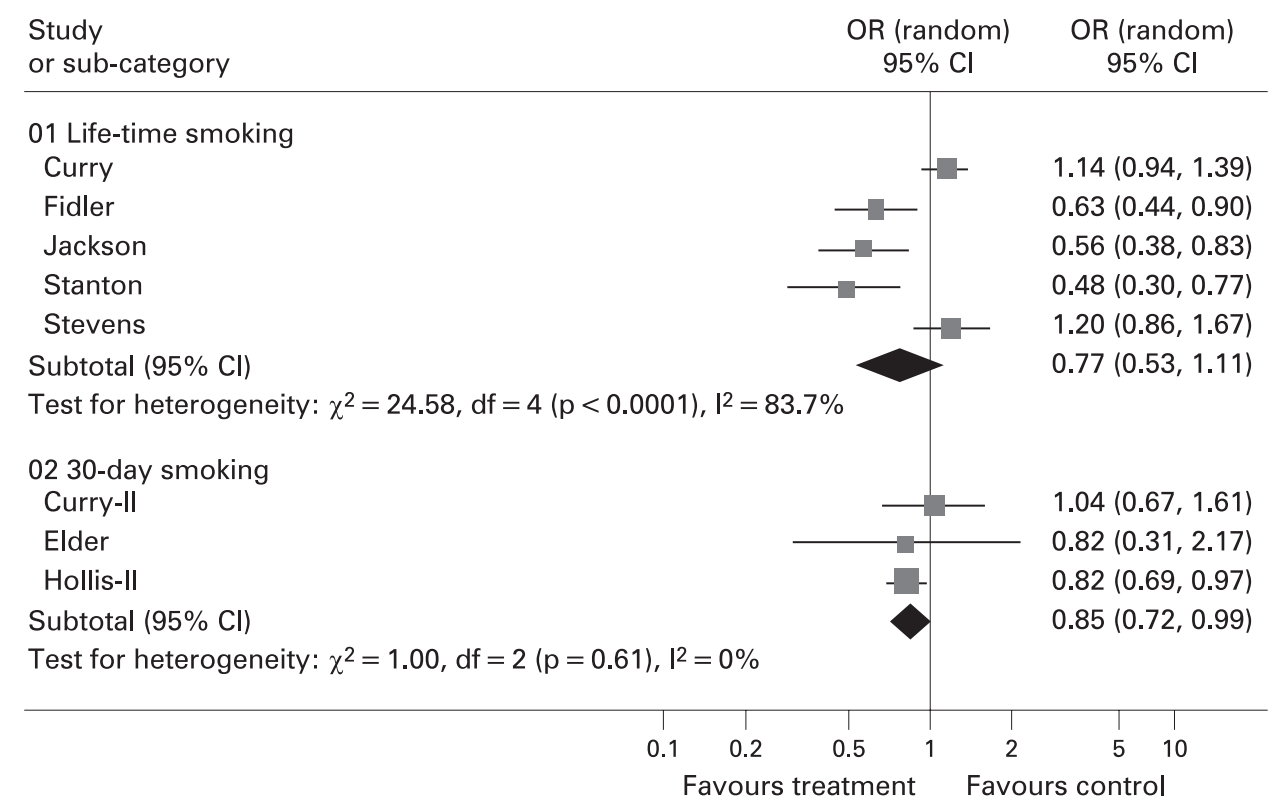

Figure 3 Meta-analysis of community-based interventions. 


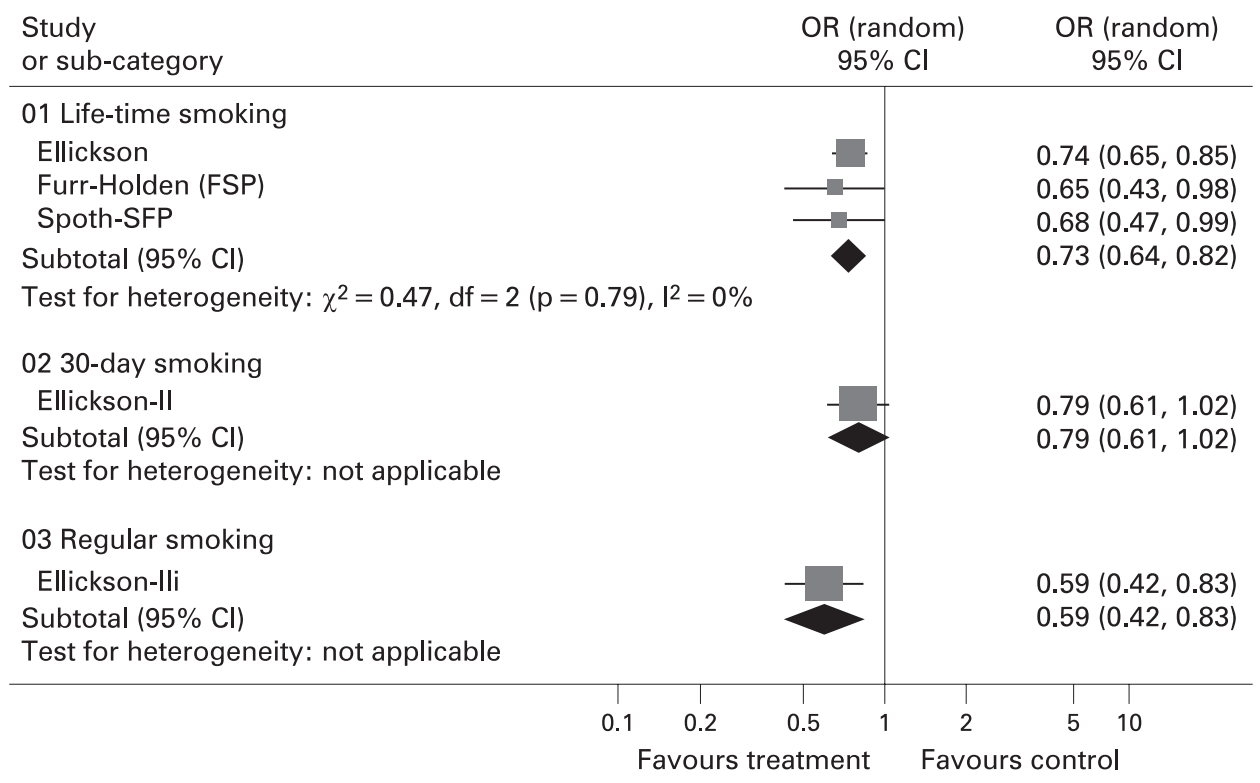

Figure 4 Meta-analysis of multisectorial interventions.

were continued in the majority of control groups in schoolbased and multisectorial interventions. This might explain some of the greater intervention effects identified for communitybased interventions. Fourthly, calculated pooled effect estimates can be sensitive to the number of studies, availability of appropriate outcome measures, the choice of outcomes and other underlying assumptions. In the present review, however, the attempt was made to test for the validity of pooled estimates by performing appropriate sensitivity analyses. These indicated that estimated pooled effects were robust in the majority of cases. It should be noted, however, that pooled effects were frequently associated with high degrees of statistical heterogeneity and should be considered cautiously. Fifthly, the chosen time cut-off for study inclusion could possibly introduce bias. This approach was chosen, however, to put an emphasis on recent literature. Finally, despite the highly sensitive search strategy and exhaustive manual search of reference lists performed in the present review, publication bias is to be expected. The attempt was thus made to investigate publication bias by creating a funnel plot diagram of all included studies (fig 5). The diagram showed some asymmetry, with less precise studies being more likely to report favourable

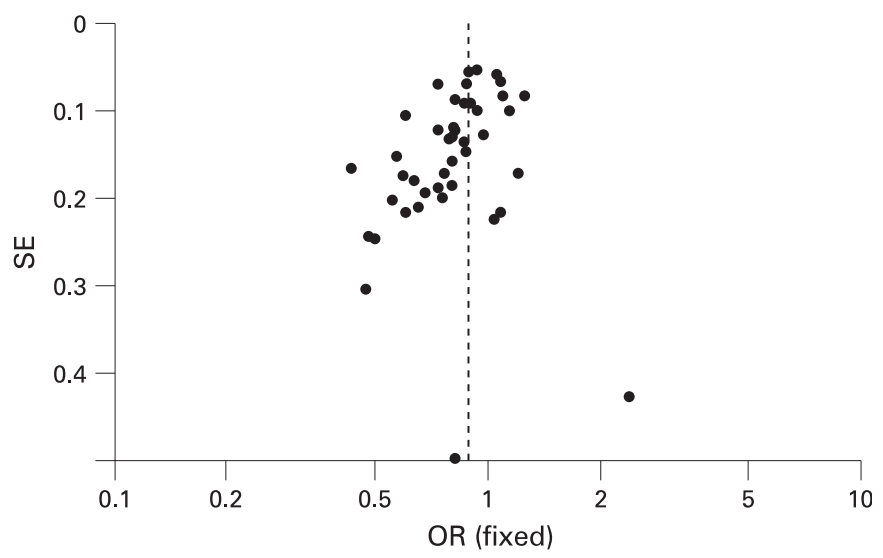

Figure 5 Funnel plot diagram representing all reported outcome measures. intervention effects. This indicates that publication bias is likely and that the results of the present review may overestimate the true long-term effectiveness of behavioural intervention strategies.

This systematic review attempted to evaluate the long-term effectiveness of behavioural smoking prevention strategies. It should be pointed out, however, that long-term was defined as a minimum of 12 months. None of the methodologically reliable studies specifically followed adolescents until adulthood. Because smoking rates among youths increase rapidly up to early adulthood, the sustainability of intervention effects is unclear. Saying this, it should be pointed out, that included studies did not indicate decreasing intervention effectiveness with increasing length of study duration. In fact, with one exception ${ }^{38}$ all studies with a study duration greater than 36 months provided evidence of intervention effectiveness. ${ }^{35} 38404245465062$

\section{What this paper adds}

- This study evaluates and compares the effectiveness of school-based, community-based and multisectorial behavioural smoking prevention strategies.

- The review indicates that the evidence for the effectiveness of current school-based smoking prevention strategies alone is inconclusive and that there is more conclusive evidence for the effectiveness of community-based and multisectorial smoking prevention strategies.

- However, even current and comprehensive behavioural smoking prevention programs are only associated with a moderate reduction in smoking prevalence and they should be complemented by appropriate environmental strategies to achieve sustainable reductions in smoking rates on a broad population basis.

- This study further indicates, that there is currently a lack of studies investigating specific intervention components, which could help design more effective intervention strategies in the future. In addition, it should be noted that the growing complexity of current smoking prevention programs warrants high-quality cost-effectiveness studies. 
In summary, the present review of behavioural interventions for smoking prevention provides moderate evidence for the long-term effectiveness of community-based and multisectorial interventions. For school-based interventions, however, the evidence of effectiveness was less convincing. Indeed, even in studies providing evidence of effectiveness, reductions in smoking rates were only modest. In view of the limited comparability of school-based, community-based and multisectorial strategies, however, it would not be justifiable to discard school-based prevention strategies altogether. On the contrary, it seems essential to facilitate the effectiveness of existing school-based prevention programs by supplementing them with community-based and family-based interventions. In addition, population-wide and environmental smoking prevention strategies should be continued and broadened to achieve meaningful and sustainable reductions in smoking rates among children and youth. There remains a great need for rigorous studies that investigate and identify the specific, effective components of various interventions. Moreover, due to the increasing complexity of recent interventions, high-quality costeffectiveness analyses are also warranted to identify the most cost-effective ways to reach a wider population.

Funding: This systematic review was commissioned and funded by the German Institute of Medical Documentation and Information (DIMDI).

Competing interests: None.

\section{REFERENCES}

1. Boffetta P, Agudo A, Ahrens W, et al. Multicenter case-control study of exposure to environmental tobacco smoke and lung cancer in Europe. J Natl Cancer Inst 1998;90:1440-50.

2. US Department of Health and Human Services. The health consequences of smoking: cardiovascular disease. Rockville, Maryland, USA: US Department of Health and Human Services, Office of Smoking and Health, 1983.

3. US Department of Health and Human Services. Summary of the health consequences of smoking. Chronic obstructive lung disease Report of the Surgeon General. Rockville, Maryland, USA: US Department of Health and Human Services, Public Health Service, National Institutes of Health, National Heart, Lung and Blood Institute, 2004

4. He J, Vupputuri S, Allen $\mathrm{K}$, et al. Passive smoking and the risk of coronary heart disease - a meta-analysis of epidemiologic studies. N Engl J Med 1999;340:920-6.

5. Bonita R, Duncan J, Truelsen T, et al. Passive smoking as well as active smoking increases the risk of acute stroke. Tob Control 1999:8:156-60.

6. Ezzati M, Lopez AD. Estimates of global mortality attributable to smoking in 2000. Lancet 2003;362:847-52.

7. Warren CW, Jones NR, Peruga A, et al. Global youth tobacco surveillance, 20002007. MMWR Surveill 2008;57:1-28.

8. Bundeszentrale für Gesundheitliche Aufklärung. Neue Ergebnisse zur Entwicklung des Rauchverhaltens von Jugendlichen (change in smoking rates among adolescents in Germany). http://www.bzga.de/stadien (accessed 12 June 2008).

9. Lantz PM, Jacobson PD, Warner KE, et al. Investing in youth tobacco control: a review of smoking prevention and control strategies. Tob Control 2000;9:47-63.

10. Thomas M. In: Walker A, ed. Living in Britain: results from the 1996 General Household Survey. London, UK: The Stationary Office, 1998.

11. Bruvold WH. A meta-analysis of adolescent smoking prevention programs Am J Public Health 1993;83:872-80.

12. Tobler NS. Meta-analysis of 143 adolescent drug prevention programs: quantitative outcome results of program participants compared to a control or comparison group. J Drug Iss 1986;16:537-67.

13. US Department of Health and Human Services. Mortality trends for selected smoking-related cancers and breast cancer - United States, 1993. Report no. 42. Washington, DC, USA: US Department of Health and Human Services, 1993.

14. US Department of Health and Human Services. Guidelines for school health programs to prevent tobacco use and addiction, 1994. Report no. 43. Washington, DC, USA: US Department of Health and Human Services, 1994.

15. US Department of Health and Human Services. Preventing tobacco use among young people: a report of the Surgeon General. Washington, DC, USA: US Department of Health and Human Services, Public Health Service, Centers for Disease Control and Prevention, National Center for Chronic Disease Prevention and Health Promotion, Office on Smoking and Health, 1994.

16. de Vries $\mathbf{H}$, Mudde A, Kremers S, et al. The European Smoking Prevention Framework Approach (ESFA): short-term effects. Health Educ Res 2003;18:649-63.

17. Wiehe SE, Garrison MM, Christakis DA, et al. A systematic review of school-based smoking prevention trials with long-term follow-up. J Adolesc Health 2005;36:162-9.
18. Peterson AV Jr, Kealey KA, Mann SL, et al. Hutchinson Smoking Prevention Project: long-term randomized trial in school-based tobacco use prevention--results on smoking. J Natl Cancer Inst 2000;92:1979-91.

19. Skara S, Sussman S. A review of 25 long-term adolescent tobacco and other drug use prevention program evaluations. Prev Med 2003;37:451-74.

20. Hwang MS, Yeagley KL, Petosa R. A meta-analysis of adolescent psychosocial smoking prevention programs published between 1978 and 1997 in the United States. Health Educ Behav 2004;31:702-19.

21. Botvin GJ, Baker E, Dusenbury L, et al. Long-term follow-up results of a randomized drug abuse prevention trial in a white middle-class population. JAMA 1995;273:1106-12.

22. Eisen M, Zellman GL, Massett HA, et al. Evaluating the Lions-Quest 'Skills for Adolescence' drug education program: first-year behavior outcomes. Addictive Behav 2002;27:619-32.

23. Sowden A, Arblaster L, Stead L. Community interventions for preventing smoking in young people. Cochrane Database Syst Rev 2003;1:CD001291.

24. Hancock L, Sanson-Fisher R, Perkins J, et al. The effect of a community action intervention on adolescent smoking rates in rural Australian towns: the CART project. Cancer Action in Rural Towns. Prevent Med 2001;32:332-40.

25. Curry SJ, Hollis J, Bush T, et al. A randomized trial of a family-based smoking prevention intervention in managed care. Prev Med 2003;37:617-26.

26. Harbour R, Miller J. A new system for grading recommendations in evidence based guidelines. BMJ 2001:323:334-6.

27. DerSimonian R, Laird N. Meta-analysis in clinical trials. Control Clin Trials 1986; 7:177-88

28. Higgins J P T, Green S. Cochrane Handbook for systematic reviews of interventions 4.2.6. 2006. http://www.cochrane-handbook.org/ (accessed 12 June 2008).

29. Botvin GJ, Griffin KW, Diaz T, et al. Drug abuse prevention among minority adolescents: posttest and one-year follow-up of a school-based preventive intervention. Prev Sci 2001;2:1-13.

30. Johnson CA, Unger JB, Ritt-Olson A, et al. Smoking prevention for ethnically diverse adolescents: 2-year outcomes of a multicultural, school-based smoking prevention curriculum in southern California. Prev Med 2005;40:842-52.

31. Aveyard $\mathbf{P}$, Sherratt E, Almond J, et al. The change-in-stage and updated smoking status results from a cluster-randomized trial of smoking prevention and cessation using the transtheoretical model among British adolescents. Prev Med 2001;33:31324.

32. Chou C-P, Li Y, Unger JB, et al. A randomized intervention of smoking for adolescents in urban Wuhan, China. Prev Med 2006;42:280-5.

33. Eisen M, Zellman GL, Murray DM. Evaluating the Lions-Quest 'Skills for Adolescence' drug education program: second-year behavior outcomes. Addictive Behav 2003:28:883-97.

34. Hollis JF, Polen MR, Whitlock EP, et al. Teen reach: Outcomes from a randomized controlled trial of a tobacco reduction program for teens seen in primary medical care. Pediatrics 2005;115:981-9.

35. Jackson C, Dickinson D. Enabling parents who smoke to prevent their children from initiating smoking: results from a 3-year intervention evaluation. Arch Ped Adolescent Med 2006;160:56-62

36. Fidler W, Lambert TW. A prescription for health: a primary care based intervention to maintain the non-smoking status of young people. Tob Control 2001:10:23-6.

37. Stanton B, Cole M, Galbraith J, et al. Randomized trial of a parent intervention: parents can make a difference in long-term adolescent risk behaviors, perceptions, and knowledge. Arch Ped Adolescent Med 2004;158:947-55.

38. Stevens MM, Olson AL, Gaffney CA, et al. A pediatric, practice-based, randomized trial of drinking and smoking prevention and bicycle helmet, gun, and seatbelt safety promotion. Pediatrics 2002;109:490-7.

39. Ellickson PL, McCaffrey DF, Ghosh-Dastidar B, et al. New inroads in preventing adolescent drug use: results from a large-scale trial of project ALERT in middle schools. Am J Pub Health 2003;93:1830-6.

40. Furr-Holden CDM, lalongo NS, Anthony JC, et al. Developmentally inspired drug prevention: Middle school outcomes in a school-based randomized prevention trial. Drug Alcohol Depend 2004;73:149-58.

41. Reddy KS, Arora M, Perry CL, et al. Tobacco and alcohol use outcomes of a schoolbased intervention in New Delhi. Am J Health Behav 2002;26:173-81.

42. Simons-Morton B, Haynie D, Saylor K, et al. The effects of the going places program on early adolescent substance use and antisocial behavior. Prev Sci 2005;6:187-97.

43. Perry CL, Komro KA, Veblen-Mortenson S, et al. A randomized controlled trial of the middle and junior high school D.A.R.E. and D.A.R.E. Plus programs. Arch Ped Adolescent Med 2003;157:178-84.

44. Spoth RL, Redmond C, Trudeau L, et al. Longitudinal substance initiation outcomes for a universal preventive intervention combining family and school programs. Psychol Addict Behav 2002;16:129-34.

45. Schinke SP, Schwinn TM, Di NJ, et al. Reducing the risks of alcohol use among urban youth: three-year effects of a computer-based intervention with and without parent involvement. J Stud Alcohol 2004;65:443-9.

46. Spoth R, Redmond C, Shin C, et al. Brief family intervention effects on adolescent substance initiation: School-level growth curve analyses 6 years following baseline. J Consult Clin Psychol 2004;72:535-42.

47. Elder JP, Litrownik AJ, Slymen DJ, et al. Tobacco and alcohol use-prevention program for Hispanic migrant adolescents. Am J Prevent Med 2002;23:269-75.

48. Thomas R, Perera R. School-based programmes for preventing smoking. Cochrane Database Syst Rev 2006;3:CD001293. 
49. Audrey S, Holliday J, Campbell R. It's good to talk: adolescent perspectives of an informal, peer-led intervention to reduce smoking. Social Sci Med 2006;63:320-34.

50. Bond L, Patton G, Glover S, et al. The Gatehouse Project: can a multilevel school intervention affect emotional wellbeing and health risk behaviours? J Epidemiol Comm Health 2004;58:997-1003

51. Brown KS, Cameron R, Madill C, et al. Outcome evaluation of a high school smoking reduction intervention based on extracurricular activities. Prev Med 2002;35:506-10.

52. Byrne DG, Mazanov J. Prevention of adolescent smoking: a prospective test of three models of intervention. J Subst Use 2005;10:363-74.

53. Crone MR, Reijneveld SA, Willemsen MC, et al. Prevention of smoking in adolescents with lower education: a school based intervention study. J Epidemiol Comm Health 2003;57:675-80.

54. Hamilton G, Cross D, Resnicow K, et al. A school-based harm minimization smoking intervention trial: outcome results. Addiction 2005;100:689-700.

55. Schulze A, Mons U, Edler L, et al. Lack of sustainable prevention effect of the 'Smoke-Free Class Competition' on German pupils. Prevent Med 2006;42:33-9.

56. Share M, Quinn M, Ryan C. Evaluation of a 5-year school-based county-wide smoking education programme. Irish Med J 2004;97:264-7.
57. Sussman S, Sun P, McCuller WJ, et al. Project towards no drug abuse: two-year outcomes of a trial that compares health educator delivery to self-instruction. Prevent Med 2003;37:155-62.

58. D'Onofrio CN, Moskowitz JM, Braverman MT. Curtailing tobacco use among youth: evaluation of project 4-health. Health Educ Behav 2002;29:656-82.

59. Ausems M, Mesters I, van BG, et al. Effects of in-school and tailored out-of-school smoking prevention among Dutch vocational school students. Health Educ Res 2004;19:51-63.

60. de Vries H, Mudde A, Leijs I, et al. The European Smoking Prevention Framework Approach (EFSA): an example of integral prevention. Health Educ Res 2003;18:611-26.

61. de Vries H, Dijk F, Wetzels J, et al. The European Smoking Prevention Framework Approach (ESFA): effects after 24 and 30 months. Health Educ Res 2006;21:116-32.

62. Brown EC, Catalano RF, Fleming CB, et al. Adolescent substance use outcomes in the Raising Healthy Children project: a two-part latent growth curve analysis. J Consult Clin Psychol 2005:73:699-710.

63. Schofield MJ, Lynagh M, Mishra G. Evaluation of a Health Promoting Schools program to reduce smoking in Australian secondary schools. Health Educ Res 2003;18:678-92.

64. Winkleby MA, Feighery $\mathrm{E}$, Dunn M, et al. Effects of an advocacy intervention to reduce smoking among teenagers. Arch Ped Adolescent Med 2004;158:269-75.

\section{The lighter side}

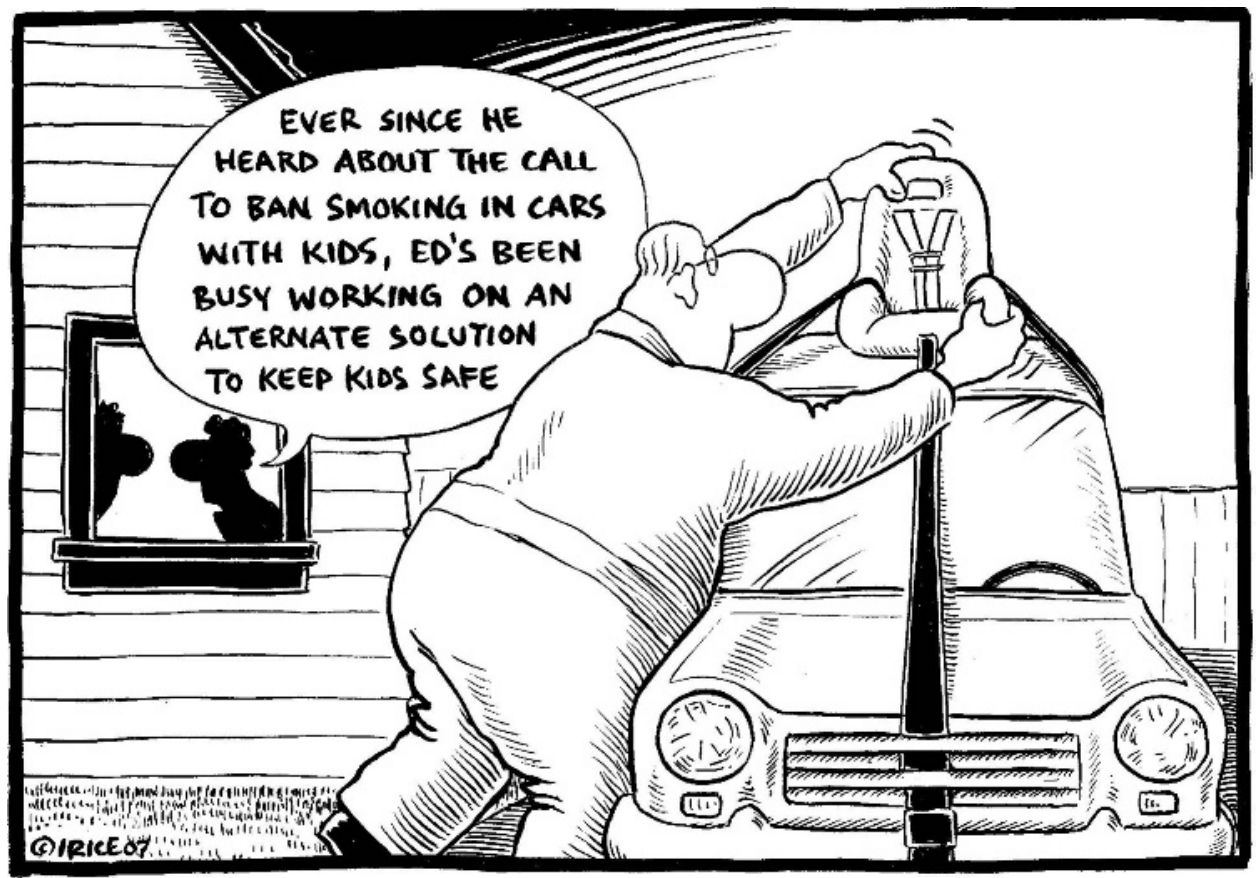

(C) Ingrid Rice 2007 